\title{
Predictive and Prognostic Value of CYFRA 21-1 for Advanced Non-small Cell Lung Cancer Treated with EGFR-TKIs
}

\author{
AKIRA TAKEUCHI ${ }^{1}$, TETSUYA OGURI ${ }^{1}$, KAZUKI SONE $^{1}$, KEIMA ITO $^{1}$, YUKI KITAMURA ${ }^{1}$, \\ YOSHITSUGU INOUE ${ }^{1}$, TAKAMITSU ASANO ${ }^{1}$, SATOSHI FUKUDA ${ }^{1}$, \\ YOSHIHIRO KANEMITSU ${ }^{1}$, OSAMU TAKAKUWA ${ }^{2}$, HIROTSUGU OHKUBO ${ }^{1}$, \\ MASAYA TAKEMURA ${ }^{1}$, KEN MAENO $^{1}$, YUTAKA ITO ${ }^{1}$ and AKIO NIIMI ${ }^{1}$ \\ ${ }^{1}$ Department of Respiratory Medicine, Allergy and Clinical Immunology, \\ Nagoya City University Graduate School of Medical Sciences, Nagoya, Japan; \\ ${ }^{2}$ Department of Education and Research Center for Advanced Medicine, \\ Nagoya City University Graduate School of Medical Sciences, Nagoya, Japan
}

\begin{abstract}
Background: Tyrosine kinase inhibitors (TKIs) directed against epidermal growth factor receptor (EGFR) are important in the treatment of non-small cell lung cancer (NSCLC), especially those harboring EGFR mutations. But little is known regarding the clinical value of serum tumor marker levels measured prior to treatment. Patients and Methods: We retrospectively reviewed 95 patients with advanced NSCLC treated with EGFR-TKIs, and inspected the relationship between serum tumor marker levels and clinical outcome. Results: Forty-three patients with an elevated serum level of cytokeratin 19 fragment (CYFRA 21-1) had shorter progression-free (PFS) and overall (OS) survival than 52 patients with normal serum CYFRA 21-1 levels (99 vs. 123.5 days $p=0.011$; and 385 vs. 607 days, respectively, $p=0.001$ ). Regardless of EGFR mutation status, patients had shorter progression-free survival when serum CYFRA 21-1 was elevated. Conclusion: Serum CYFRA 21-1 level may be a predictive factor for patients with NSCLC treated with EGFRTKIs, regardless of EGFR mutation status.
\end{abstract}

Tyrosine kinase inhibitors (TKIs) directed against epidermal growth factor receptor (EGFR) are very effective against nonsmall cell lung cancer (NSCLC) harboring EGFR mutations (1-6). Erlotinib, one of the first-generation EGFR-TKIs, is a

Correspondence to: Tetsuya Oguri, Department of Respiratory Medicine, Allergy and Clinical Immunology, Nagoya City University Graduate School of Medical Sciences, 1 Kawasumi, Mizuho-cho, Mizuho-ku, Nagoya, Aichi 467-8601, Japan. E-mail: t-oguri@med.nagoya-cu.ac.jp

Key Words: Cytokeratin 19 fragment, tumor marker, EGFR-TKI, non-small-cell lung cancer. treatment for NSCLC without EGFR mutation (7). Beyond EGFR mutation however, there are no clear predictive clinical markers for the therapeutic effect of EGFR-TKIs.

Meta-analysis has demonstrated that an elevated serum level of cytokeratin 19 fragment (CYFRA 21-1) may be associated with poor prognosis in patients with NSCLC (8). CYFRA 21-1 is usually used as a tumor marker in lung cancer, especially in squamous cell tumors (9). It has also been reported that an increase in pretreatment serum level of CYFRA 21-1 and carcinoembryonic antigen (CEA) are associated with poor outcome in patients with NSCLC treated with erlotinib (10). There is little information, however, about the predictive value of serum tumor markers for patients with advanced NSCLC treated with EGFR-TKIs. The present study aimed to examine the predictive and prognostic value of pretreatment serum CYFRA 21-1 and CEA levels in patients with advanced NSCLC treated with first- and second-generation TKIs (gefitinib, erlotinib and afatinib).

\section{Patients and Methods}

We retrospectively screened cases of advanced NSCLC treated with EGFR-TKI therapy at Nagoya City University Hospital (Japan) between June 2006 and August 2016. All patients had stage IIIB or IV disease. Patients received gefitinib (250 mg/day), erlotinib $(150 \mathrm{mg} /$ day), or afatinib (40 mg/day) until detection of progressive disease (PD) or intolerable toxicity. Dose interruption or reduction was permitted in cases of treatment-related toxicity. Our Institutional Ethics Committee approved the protocol of this study (No. 1301), and all medical data were anonymized.

Serum CYFRA 21-1 and CEA levels were measured prior to initial chemotherapy. The serum CEA level was measured by using a commercial electrochemiluminescence immunoassay on the HISCL-5000 system (Sysmex, Hyogo, Japan). Serum CYFRA 211 level was measured using a commercial electrochemiluminescence 
immunoassay on a LUMIPULSE Presto II system (Fujirebio Inc., Tokyo, Japan). Measurements were performed at our hospital, using cut-off values of $3.5 \mathrm{ng} / \mathrm{ml}$ for CYFRA $21-1$, and $5.0 \mathrm{ng} / \mathrm{ml}$ for CEA, which were the upper limit of normal values at our hospital.

Statistical analysis. Progression-free survival (PFS) was defined as the time from the first day of TKI treatment until the date of disease progression, death, or last follow-up. Overall survival (OS) was defined as the time from the first day of TKI treatment until the date of death or last follow-up. PFS and OS were analyzed using the Kaplan-Meier method and compared using the log-rank test, with $p<0.05$ considered statistically significant. Multivariate analysis using a Cox proportional hazards model was performed to identify associations between clinical characteristics and survival, using a probability of $p=0.10$ as the threshold for adding a covariable to or removing it from the model, with $p<0.05$ again considered significant. All statistical analyses were performed with EZR (Saitama Medical center, Jichi Medical University, Saitama, Japan), which is a graphical use interface for $\mathrm{R}$ (the $\mathrm{R}$ Foundation for Statistical Computing, Vienna, Austria). More precisely, it is a modified version of $\mathrm{R}$ commander designed to add statistical functions frequently used in biostatistics (11).

\section{Results}

The clinicopathological characteristics of the 95 patients are shown in Table I. All patients had a performance status of 0 or 1. Fifty-four patients carried an EGFR mutation (29 had exon 19 deletion, 23 had exon 21 L858R, and two had exon $21 \mathrm{~L} 861 \mathrm{Q}), 34$ patients had wild-type $E G F R$, and in seven patients the EGFR mutation status was not evaluated. Fortythree patients had an elevated serum level of CYFRA 21-1 $(>3.5 \mathrm{ng} / \mathrm{ml})$ prior to the start of EGFR-TKI treatment, and 69 patients had an elevated serum level of CEA $(>5.0 \mathrm{ng} / \mathrm{ml})$. Both PFS and OS were significantly shorter in the group with an elevated level of CYFRA 21-1 than those with normal serum levels (99 vs. 123.5 days, $p=0.011$; and $385 v s .607$ days, $p=0.001$, respectively; Figure $1 \mathrm{~A}$ and B). In contrast, there was no significant difference in PFS or OS between those who had elevated or normal CEA level (124 vs. 97 days, $p=0.757$; and $542 v s .357$ days, $p=0.059$, respectively; Figure $1 C$ and D). In univariate analysis, CYFRA 21-1 level and $E G F R$ mutation were significant factors for PFS, while CYFRA 21-1 level, EGFR mutation, and tumor pathology were significant factors for OS (Table II). In multivariate analysis, CYFRA 21-1 and EGFR mutation were significant factors for both PFS [hazard ratio (HR) $=2.17, p<0.001$; $\mathrm{HR}=2.92, p=0.001$, respectively; Table III] and $\mathrm{OS}(\mathrm{HR}=2.29$, $p=0.001$; and $\mathrm{HR}=4.72, p<0.001$, respectively; Table IV).

In patients with $E G F R$ mutation, PFS and OS were both found to be significantly shorter in those with elevated CYFRA 21-1 than those with normal levels (168 vs. 244.5 days, $p=0.032 ;$ and 471 vs. 1023 days, $p<0.001$, respectively; Figure $2 \mathrm{~A}$ and $\mathrm{B})$. On the other hand, in patients with wild-type/unknown EGFR status, there was again a significantly shorter PFS but only a trend for shorter
Table I. Patient characteristics $(n=95)$.

\begin{tabular}{|c|c|}
\hline Characteristic & Value \\
\hline Median age (range), years & $66(43-88)$ \\
\hline \multicolumn{2}{|l|}{ Gender, $\mathrm{n}$} \\
\hline Male & 44 \\
\hline Female & 51 \\
\hline \multicolumn{2}{|l|}{ Smoking history, $\mathrm{n}$} \\
\hline Current or former smoker & 45 \\
\hline Never smoker & 50 \\
\hline \multicolumn{2}{|l|}{ Disease stage, $\mathrm{n}$} \\
\hline IIB & 6 \\
\hline IV & 89 \\
\hline \multicolumn{2}{|l|}{ Pathology, n } \\
\hline Squamous cell carcinoma & 12 \\
\hline Non-squamous cell carcinoma & 83 \\
\hline Adenocarcinoma & 73 \\
\hline Large cell carcinoma & 1 \\
\hline Non-small cell carcinoma & 9 \\
\hline \multicolumn{2}{|l|}{ EGFR mutation status, $\mathrm{n}$} \\
\hline Mutated & 54 \\
\hline Ex19 Del & 29 \\
\hline Ex21 L858R & 23 \\
\hline Ex21 L861Q & 2 \\
\hline Wild-type/unknown & 41 \\
\hline Wild-type & 34 \\
\hline Unknown & 7 \\
\hline \multicolumn{2}{|l|}{ No. of prior treatment $\mathrm{s}, \mathrm{n}$} \\
\hline 0 & 37 \\
\hline 1 & 22 \\
\hline 2 & 12 \\
\hline More & 24 \\
\hline \multicolumn{2}{|l|}{ Type of TKI, n } \\
\hline Gefitinib & 38 \\
\hline Erlotinib & 55 \\
\hline Afatinib & 2 \\
\hline Median CEA (range), ng/ml & $15.6(1.1-4609)$ \\
\hline Median CYFRA 21-1 (range), ng/ml & $3.2(0.6-83.6)$ \\
\hline
\end{tabular}

EGFR, Epidermal growth factor receptor; TKI, tyrosine kinase inhibitor; CEA, carcinoembryonic antigen; CYFRA 21-1, cytokeratin 19 fragment.

OS in those with elevated CYFRA 21-1 compared to those with normal levels (30 vs. 53.5 days, $p=0.027$; and $106 v s$. 252.5 days, $p=0.115$, respectively; Figure $2 \mathrm{C}$ and $\mathrm{D}$ ). There was no association between CEA and length of PFS or OS in EGFR mutation-positive patients (193 vs. 362.5 days, $p=0.297$; and $767 v s .1314$ days, $p=0.951$, respectively), nor in those with wild-type/unknown EGFR status (48 vs. 45.5 days, $p=0.66$; and $194 v s$. 285 days, $p=0.827$, respectively).

\section{Discussion}

In this retrospective study, EGFR-TKI-treated patients with an elevated serum level of CYFRA 21-1 had shorter PFS and OS times than those with normal levels. In contrast, an 

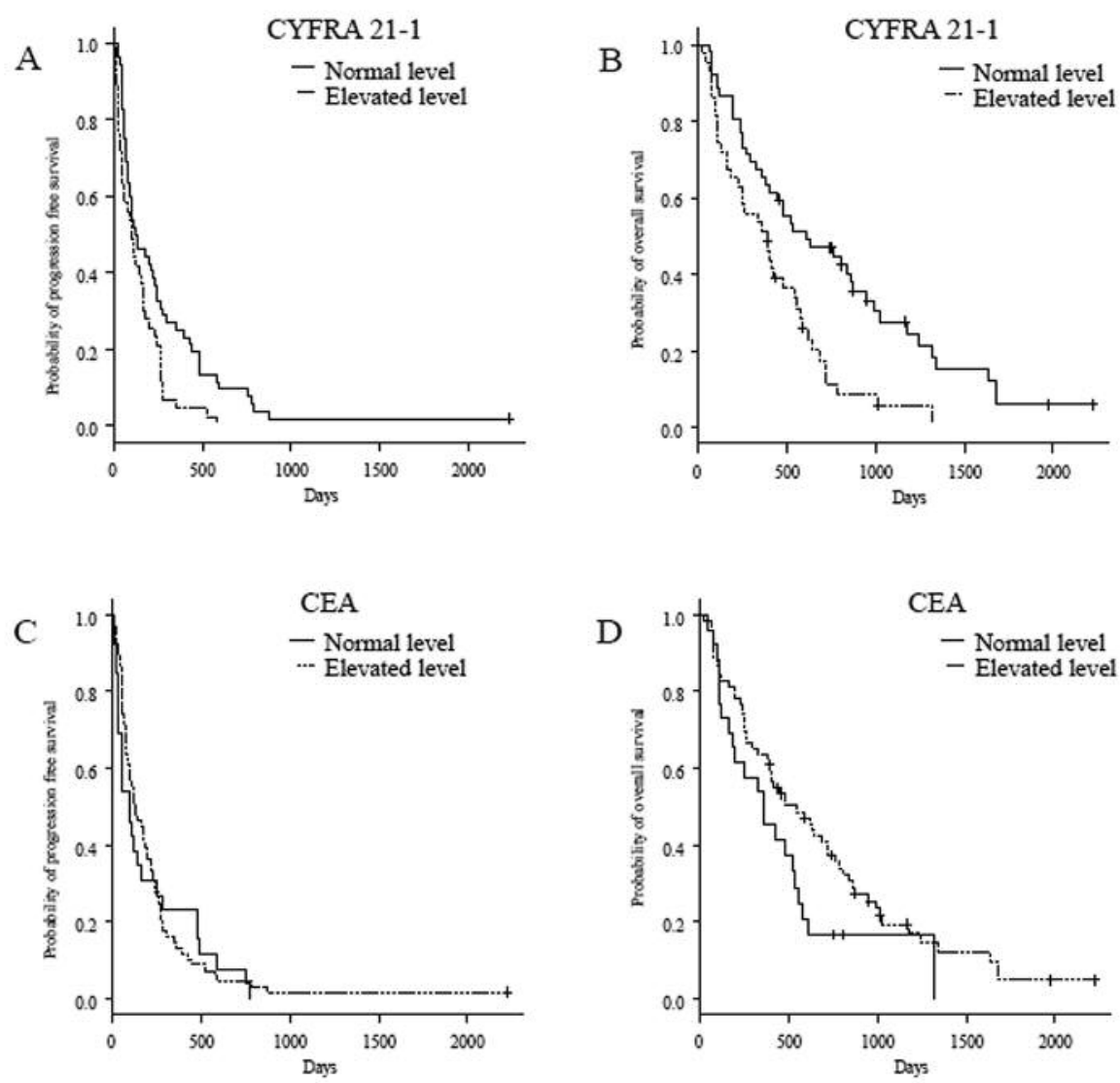

Figure 1. Kaplan-Meier plots of progression-free (PFS) (A, C) and overall (OS) (B,D) survival according to serum cytokeratin 19 fragment (CYFRA 21-1) level $(A, B)$ and carcinoembryonic antigen (CEA) level $(C, D)$. The median PFS durations in the group with normal and that with elevated serum CYFRA 21-1 were 123.5 [95\% confidence interval $(C I)=83-226$ ] days and $99(95 \%$ CI=46-164) days, respectively $(p=0.011)(A)$. The corresponding median OS durations were 607 (95\% CI=374-873) days and 385 (95\% CI=175-542) days, respectively ( $p=0.001)(B)$. The median PFS durations in the group with normal and that with elevated serum CEA were 97 (95\% CI=33-164) days and 124 (95\% CI=83-192) days, respectively ( $p=0.757)(C)$. The corresponding median OS durations were 357 (95\% CI=158-526) days and 542 (95\% CI=374-718) days, respectively $(p=0.059)(D)$.

elevated serum level of CEA was not found to influence the duration of PFS or OS. In multivariate analysis, CYFRA 211 and EGFR mutation were significant factors for both PFS and OS. It is known that EGFR-TKIs for patients with advanced NSCLC harboring EGFR mutation improve PFS compared with chemotherapy (1-6). In our subgroup analysis, an elevated level of serum CYFRA 21-1 was associated with shorter PFS and OS in EGFR-mutated patients, and shorter PFS in those with with wild-type/unknown EGFR status. Thus, CYFRA 21-1 was a predictive factor not only in EGFR mutation-positive patients treated with EGFR-TKIs, but also in those with wild-type/unknown EGFR status.

A previous meta-analysis reported that an elevated serum level of CYFRA 21-1 is associated with shorter OS in patients with advanced NSCLC (8), an observation that our findings are consistent with. It has been shown that CYFRA 21-1 is a predictive marker of PFS in patients with NSCLC with EGFR mutation who were treated with EGFR-TKIs (12). An elevated serum level of CYFRA 21-1 has also been associated with poor PFS in patients with NSCLC treated with EGFR-TKIs (10). However in this study, because EGFR status was not considered, it was difficult to determine how much effect CYFRA 21-1 had on PFS and OS in patients with NSCLC with wild-type/unknown $E G F R$ status. Our study showed that elevation of serum CYFRA 21-1 was also a negative predictive factor for PFS in patients with NSCLC with wild-type EGFR or unknown EGFR status. Since elevated CYFRA 21-1 has been associated with the presence of mediastinal lymph node metastases and poor performance status (9), this marker may reflect tumor volume. In contrast, serum CEA had no association with PFS or OS in our study. Not only tumor volume but also tumor characteristics may have an important role in determining patient survival. 
Table II. Univariate analysis of progression-free (PFS) and overall (OS) survival by log-rank test.

\begin{tabular}{|c|c|c|c|c|c|c|}
\hline \multirow[t]{2}{*}{ Factor } & \multirow[t]{2}{*}{ Category } & \multirow[t]{2}{*}{$\mathrm{n}$} & \multicolumn{2}{|c|}{ PFS } & \multicolumn{2}{|c|}{ OS } \\
\hline & & & Median (days) & $p$-Value & Median (days) & $p$-Value \\
\hline \multirow[t]{2}{*}{ Age } & $<75$ & 69 & 105 & 0.626 & 471 & 0.668 \\
\hline & $\geq 75$ & 26 & 136.5 & & 397 & \\
\hline \multirow[t]{2}{*}{ Gender } & Female & 51 & 116 & 0.475 & 519 & 0.227 \\
\hline & Male & 44 & 100.5 & & 329.5 & \\
\hline \multirow[t]{2}{*}{ Smoking history } & Never & 50 & 123.5 & 0.22 & 630 & 0.054 \\
\hline & Current or former & 45 & 99 & & 330 & \\
\hline \multirow[t]{2}{*}{ Disease Stage } & IIIB & 6 & 184 & 0.283 & 366 & 0.291 \\
\hline & IV & 89 & 105 & & 471 & \\
\hline \multirow[t]{2}{*}{ Pathology } & Non-squamous & 83 & 124 & 0.098 & 476 & $<0.001$ \\
\hline & Squamous & 12 & 74 & & 145.5 & \\
\hline \multirow[t]{2}{*}{$E G F R$ mutation status } & Mutated & 54 & 214.5 & $<0.001$ & 777 & $<0.001$ \\
\hline & Wild-type/unknown & 41 & 46 & & 228 & \\
\hline \multirow[t]{2}{*}{ No. of prior treatments } & $0 / 1$ & 59 & 174 & $<0.001$ & 636 & $<0.001$ \\
\hline & $2 /$ more & 36 & 46 & & 233.5 & \\
\hline \multirow[t]{2}{*}{ CEA } & $\leq 5.0 \mathrm{ng} / \mathrm{ml}$ & 26 & 97 & 0.757 & 357 & 0.059 \\
\hline & $>5.0 \mathrm{ng} / \mathrm{ml}$ & 69 & 124 & & 542 & \\
\hline \multirow{2}{*}{ CYFRA 21-1 } & $\leq 3.5 \mathrm{ng} / \mathrm{ml}$ & 52 & 123.5 & 0.011 & 607 & 0.001 \\
\hline & $>3.5 \mathrm{ng} / \mathrm{ml}$ & 43 & 99 & & 385 & \\
\hline
\end{tabular}

EGFR, Epidermal growth factor receptor; CEA, carcinoembryonic antigen; CYFRA 21-1, cytokeratin 19 fragment.

Table III. Multivariate analysis of progression-free survival by Cox proportional hazards regression.

\begin{tabular}{llcc}
\hline Factor & Category & HR $(95 \% \mathrm{CI})$ & $p$-Value \\
\hline Pathology & Non-squamous & 1.00 & 0.169 \\
& Squamous & $0.61(0.31-1.23)$ & \\
EGFR mutation status & Mutated & 1.00 & 0.001 \\
& Wild-type/unknown & $2.92(1.54-5.52)$ & \\
No. of prior treatment & $0 / 1$ & 1.00 & 0.12 \\
& $2 /$ more & $1.60(0.88-2.91)$ & \\
CYFRA 21-1 & $\leq 3.5 \mathrm{ng} / \mathrm{ml}$ & 1.00 & $<0.001$ \\
& $>3.5 \mathrm{ng} / \mathrm{ml}$ & $2.17(1.38-3.40)$ & \\
\hline
\end{tabular}

HR, Hazard ratio; CI, confidence interval; EGFR, epidermal growth factor receptor; CYFRA 21-1, cytokeratin 19 fragment.

CYFRA 21-1 is a fragment of the cytokeratin 19 protein that forms part of the cytoskeleton of epithelial cells (9). Activated proteases in malignant epithelial cells increase cytokeratin degradation, with the consequent release of cytokeratin fragments, particularly fragment 19, into the blood (14). Cytokeratin 19 is thought to be expressed more widely in cases of poorly differentiated squamous cell cancer (15), where its serum levels have been shown to provide significantly greater sensitivity and specificity for the purpose of diagnosis than other histological markers (9). Due
Table IV. Multivariate analysis of overall survival by Cox proportional hazards regression.

\begin{tabular}{llcc}
\hline Factor & Category & HR $(95 \% \mathrm{CI})$ & $p$-Value \\
\hline Smoking history & Never & 1.00 & 0.621 \\
& Current or former & $0.87(0.51-1.49)$ & \\
Pathology & Non-squamous & 1.00 & 0.679 \\
& Squamous & $1.18(0.53-2.61)$ & \\
EGFR mutation status & Mutated & 1.00 & $<0.001$ \\
& Wild-type/unknown & $4.72(2.09-10.66)$ & \\
No. of prior treatments & 0/1 & 1.00 & 0.858 \\
& $2 /$ more & $1.07(0.51-2.23)$ & \\
CYFRA 21-1 & $\leq 3.5 \mathrm{ng} / \mathrm{ml}$ & 1.00 & 0.838 \\
& $>3.5 \mathrm{ng} / \mathrm{ml}$ & $1.07(0.57-1.99)$ & \\
Pathology & Non-squamous & 1.00 & 0.001 \\
& Squamous & $2.29(1.40-3.74)$ & \\
\hline
\end{tabular}

HR, Hazard ratio; CI, confidence interval; EGFR, epidermal growth factor; CEA, carcinoembryonic antigen; CYFRA 21-1, cytokeratin 19 fragment.

to the histological heterogeneity of NSCLC, it is often difficult to distinguish squamous from non-squamous cell cancer using small biopsies or cytological specimens (16). Pemetrexed, which has more efficacy in patients with nonsquamous NSCLC, in combination with a platinumderivative therapy, has been associated with shorter PFS and 

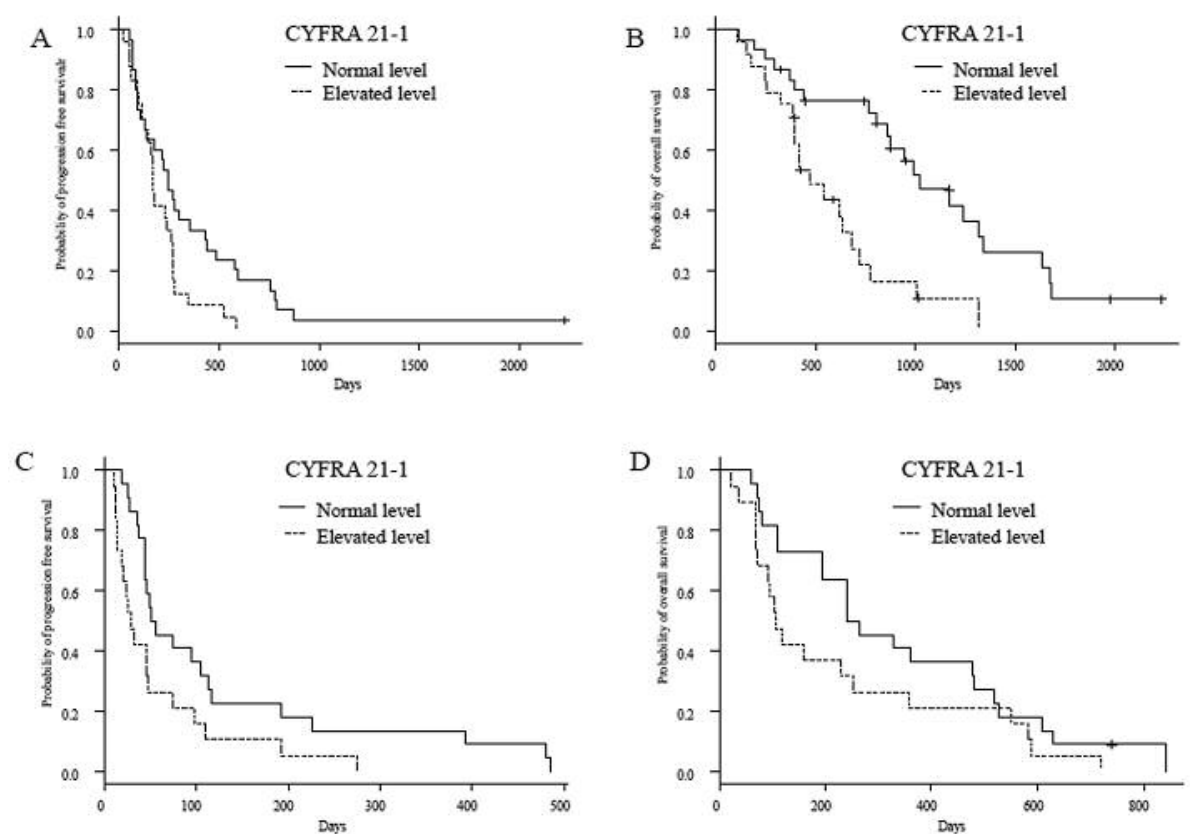

Figure 2. Kaplan-Meier plots of progression-free $(P F S)(A, C)$ and overall $(O S)(B, D)$ survival according to serum level of cytokeratin 19 fragment (CYFRA 21-1) in the group with mutation of epidermal growth factor receptor (EGFR) (A, B) and that with wild-type/unknown EGFR status (C, D). For those with EGFR mutation, the median PFS durations in those with normal and those with elevated serum CYFRA 21-1 were 244.5 [95\% confidence interval $(C I)=131-428]$ days and $168(95 \% C I=113-265)$ days, respectively $(p=0.032)(A)$. The corresponding median OS durations were 1023 $(95 \%$ $C I=805-1340)$ days and $471(95 \% C I=385-685)$ days, respectively $(p<0.001)(B)$. The median PFS durations in the group with normal and that with elevated serum CYFRA 21-1 were $53.5(95 \% C I=45-113)$ days and $30(95 \% C I=15-48)$ days, respectively $(p=0.027)(C)$. The median OS in the normal and elevated serum CYFRA 21-1 group were 252.5 (95\% CI=109-481) days and 106 (95\% CI=67-251) days, respectively $(p=0.115)(D)$.

OS, and worse disease control when the serum level of CYFRA 21-1 is elevated (17). Given this observation, higher levels of CYFRA 21-1 may be indicative of a squamous cell cancer component, explaining such differences in survival with this treatment approach.

It is important to highlight that this study has several limitations. Firstly, this was a single-institute retrospective study, so it is possible that selection bias may have affected our findings. Secondly, the molecular basis for how cytokeratin 19 plays a role in the growth and invasion of squamous cells in lung cancer is not yet understood.

In conclusion, elevated serum CYFRA 21-1 was associated with shorter PFS and OS of patients with NSCLC treated with EGFR-TKI. Importantly however, CYFRA 211 was associated with shorter PFS even in patients with wildtype or unknown EGFR status, who were poor responders to this therapy. Thus, the serum level of CYFRA 21-1 may be useful to help determine the appropriate use of EGFR-TKI therapy in all patients with NSCLC, regardless of EGFR mutation status. Further research into the molecular basis for this observation, along with prospective clinical studies, are now warranted to verify these findings.

\section{References}

1 Maemondo M, Inoue A, Kobayashi K, Sugawara S, Oizumi S, Isobe H, Gemma A, Harada M, Yoshizawa H, Kinoshita I, Fujita Y, Okinaga S, Hirano H, Yoshimori K, Harada T, Ogura T, Ando M, Miyazawa H, Tanaka T, Saijo Y, Hagiwara K, Morita S and Nukiwa T: Gefitinib or chemotherapy for non-small-cell lung cancer with mutated EGFR. N Engl J Med 362(25): 2380-2388, 2010.

2 Mitsudomi T, Morita S, Yatabe Y, Negoro S, Okamoto I, Tsurutani J, Seto T, Satouchi M, Tada H, Hirashima T, Asami K, Katakami N, Takada M, Yoshioka H, Shibata K, Kudoh S, Shimizu E, Saito H, Toyooka S, Nakagawa K and Fukuoka M: Gefitinib versus cisplatin plus docetaxel in patients with nonsmall-cell lung cancer harbouring mutations of the epidermal growth factor receptor (WJTOG3405): An open label, randomised phase 3 trial. Lancet Oncol 11(2): 121-128, 2010.

3 Rosell R, Carcereny E, Gervais R, Vergnenegre A, Massuti B, Felip E, Palmero R, Garcia-Gomez R, Pallares C, Sanchez JM, Porta R, Cobo M, Garrido P, Longo F, Moran T, Insa A, De Marinis F, Corre R, Bover I, Illiano A, Dansin E, de Castro J, Milella M, Reguart N, Altavilla G, Jimenez U, Provencio M, Moreno MA, Terrasa J, Munoz-Langa J, Valdivia J, Isla D, Domine M, Molinier O, Mazieres J, Baize N, Garcia-Campelo R, Robinet G, Rodriguez-Abreu D, Lopez-Vivanco G, Gebbia V, 
Ferrera-Delgado L, Bombaron P, Bernabe R, Bearz A, Artal A, Cortesi E, Rolfo C, Sanchez-Ronco M, Drozdowskyj A, Queralt C, de Aguirre I, Ramirez JL, Sanchez JJ, Molina MA, Taron M and Paz-Ares L: Erlotinib versus standard chemotherapy as firstline treatment for european patients with advanced EGFR mutation-positive non-small-cell lung cancer (EURTAC): A multicentre, open-label, randomised phase 3 trial. Lancet Oncol 13(3): 239-246, 2012.

4 Zhou C, Wu YL, Chen G, Feng J, Liu XQ, Wang C, Zhang S, Wang J, Zhou S, Ren S, Lu S, Zhang L, Hu C, Luo Y, Chen L, Ye M, Huang J, Zhi X, Zhang Y, Xiu Q, Ma J and You C: Final overall survival results from a randomised, phase III study of erlotinib versus chemotherapy as first-line treatment of $E G F R$ mutation-positive advanced non-small-cell lung cancer (OPTIMAL, CTONG-0802). Ann Oncol 26(9): 1877-1883, 2015.

5 Wu YL, Zhou C, Hu CP, Feng J, Lu S, Huang Y, Li W, Hou M, Shi JH, Lee KY, Xu CR, Massey D, Kim M, Shi Y and Geater SL: Afatinib versus cisplatin plus gemcitabine for first-line treatment of Asian patients with advanced non-small-cell lung cancer harbouring EGFR mutations (lux-lung 6): An open-label, randomised phase 3 trial. Lancet Oncol 15(2): 213-222, 2014.

6 Yang JC, Wu YL, Schuler M, Sebastian M, Popat S, Yamamoto N, Zhou C, Hu CP, O’Byrne K, Feng J, Lu S, Huang Y, Geater SL, Lee KY, Tsai CM, Gorbunova V, Hirsh V, Bennouna J, Orlov S, Mok T, Boyer M, Su WC, Lee KH, Kato T, Massey D, Shahidi M, Zazulina V and Sequist LV: Afatinib versus cisplatinbased chemotherapy for EGFR mutation-positive lung adenocarcinoma (LUX-LUNG 3 and LUX-LUNG 6): Analysis of overall survival data from two randomised, phase 3 trials. Lancet Oncol 16(2): 141-151, 2015.

7 Shepherd FA, Rodrigues Pereira J, Ciuleanu T, Tan EH, Hirsh V, Thongprasert S, Campos D, Maoleekoonpiroj S, Smylie M, Martins R, van Kooten M, Dediu M, Findlay B, Tu D, Johnston D, Bezjak A, Clark G, Santabarbara P and Seymour L: Erlotinib in previously treated non-small-cell lung cancer. N Engl J Med 353(2): 123-132, 2005.

8 Pujol JL, Molinier O, Ebert W, Daures JP, Barlesi F, Buccheri G, Paesmans M, Quoix E, Moro-Sibilot D, Szturmowicz M, Brechot JM, Muley $\mathrm{T}$ and Grenier J: CYFRA 21-1 is a prognostic determinant in non-small-cell lung cancer: Results of a meta-analysis in 2063 patients. Br J Cancer 90(11): 2097-2105, 2004.

9 Pujol JL, Grenier J, Daures JP, Daver A, Pujol H and Michel FB: Serum fragment of cytokeratin subunit 19 measured by CYFRA 21-1 immunoradiometric assay as a marker of lung cancer. Cancer Res 53(1): 61-66, 1993.
10 Fiala O, Pesek M, Finek J, Benesova L, Minarik M, Bortlicek Z and Topolcan O: Predictive role of CEA and CYFRA 21-1 in patients with advanced-stage NSCLC treated with erlotinib. Anticancer Res 34(6): 3205-3210, 2014.

11 Kanda Y: Investigation of the freely available easy-to-use software 'EZR' for medical statistics. Bone Marrow Transplant 48(3): 452-458, 2013.

12 Tanaka K, Hata A, Kaji R, Fujita S, Otoshi T, Fujimoto D, Kawamura T, Tamai K, Takeshita J, Matsumoto T, Monden K, Nagata K, Otsuka K, Nakagawa A, Tachikawa R, Tomii K and Katakami N: Cytokeratin 19 fragment predicts the efficacy of epidermal growth factor receptor-tyrosine kinase inhibitor in non-small-cell lung cancer harboring EGFR mutation. J Thorac Oncol 8(7): 892-898, 2013.

13 Shukuya T, Takahashi T, Kaira R, Ono A, Nakamura Y, Tsuya A, Kenmotsu H, Naito T, Kaira K, Murakami H, Endo M, Takahashi $\mathrm{K}$ and Yamamoto N: Efficacy of gefitinib for nonadenocarcinoma non-small-cell lung cancer patients harboring epidermal growth factor receptor mutations: A pooled analysis of published reports. Cancer Sci 102(5): 1032-1037, 2011.

14 Sugama Y, Kitamura S, Kawai T, Ohkubo A, Hasegawa S, Kuriyama T, Kato H, Fukuoka $M$ and Ohkawa J: Clinical usefulness of CYFRA assay in diagnosing lung cancer: Measurement of serum cytokeratin fragment. Jpn J Cancer Res 85(11): 1178-1184, 1994.

15 Broers JL, Ramaekers FC, Rot MK, Oostendorp T, Huysmans A, van Muijen GN, Wagenaar SS and Vooijs GP: Cytokeratins in different types of human lung cancer as monitored by chainspecific monoclonal antibodies. Cancer Res 48(11): 3221-3229, 1988.

16 Travis WD, Rekhtman N, Riley GJ, Geisinger KR, Asamura H, Brambilla E, Garg K, Hirsch FR, Noguchi M, Powell CA, Rusch VW, Scagliotti $G$ and Yatabe Y: Pathologic diagnosis of advanced lung cancer based on small biopsies and cytology: A paradigm shift. J Thorac Oncol 5(4): 411-414, 2010.

17 Sone K, Oguri T, Nakao M, Kagawa Y, Kurowaka R, Furuta H, Fukuda S, Uemura T, Takakuwa O, Kanemitsu Y, Ohkubo H, Takemura M, Maeno K, Ito Y, Sato H, Muramatsu $\mathrm{H}$ and Niimi A: CYFRA 21-1 as a predictive marker for non-small cell lung cancer treated with pemetrexed-based chemotherapy. Anticancer Res 37(2): 935-939, 2017.

Received July 12, 2017

Revised August 7, 2017

Accepted August 8, 2017 